EDITH T. LAMMERTS VAN BUEREN and PAUL C. STRUIK

\title{
INTEGRITY AND RIGHTS OF PLANTS: ETHICAL NOTIONS IN ORGANIC PLANT BREEDING AND PROPAGATION
}

(Accepted in revised form May 2, 2005)

\begin{abstract}
In addition to obviating the use of synthetic agrochemicals and emphasizing farming in accordance with agro-ecological guidelines, organic farming acknowledges the integrity of plants as an essential element of its natural approaches to crop production. For cultivated plants, integrity refers to their inherent nature, wholeness, completeness, species-specific characteristics, and their being in balance with their (organically farmed) environment, while accomplishing their "natural aim." We argue that this integrity of plants has ethical value, distinguishing integrity of life, plant-typic integrity, genotypic integrity, and phenotypic integrity. We have developed qualitative criteria to ethically evaluate existing practices and have applied these criteria to assess whether current plant breeding and propagation techniques violate the integrity of crop plants. This process has resulted in a design of a holistic, scientific approach of organic plant breeding and seed production. Our evaluation has met considerable criticism from mainstream (crop) scientists. We respond to the following questions: (1). Can ethics be incorporated into objective crop sciences? (2). What is the nature of the intrinsic value of plants in organic farming? We argue that criteria to take integrity into account can only be assessed from a holistic perspective and we show that a holistic approach is needed to design such ethical notions in a consistent way. The ethical notions have been further elaborated by formulating human responsibility and respect towards crop plants. Responsibility and respect can only be shown by providing crop plants the right to be nurtured and to express natural behavior at all levels of integrity.
\end{abstract}

KEY WORDS: integrity, intrinsic value, natural aim, naturalness, organic breeding, organic plant propagation, plant rights, respect

\section{INTRODUCTION}

Mainstream agronomists claim that high-input, conventional agriculture is best equipped to feed the increasing population of the world (Bindraban, 2004). They state that it not only realizes the highest yield per hectare through high inputs of water, inorganic fertilizers, and biocides, but also the highest yields per unit of input, thus also putting minimal pressure on the environment at a given level of total production. Agronomists supporting organic agriculture claim that the input efficiency in organic farming is higher, that organic farming is safer; more environmentally friendly and 
ecologically more sustainable; has more respect for natural resources, animals, and plants; produces healthier food; and establishes production systems in which the quality of life is higher. Research to support or falsify claims from both sides still continues.

The scientific debate on the pros and cons of conventional and organic agriculture has recently increased in intensity, but its character has also changed. Essential was the decision to ban genetically modified crops (GMCs) in organic farming. This decision resulted in reproaches from mainstream scientists that organic farming refused to use important, innovative tools to solve its major agronomic problems. It also resulted in hefty discussions on co-existence of organic (without GMCs) and conventional (with GMCs) farming. The discussions on this ban have underlined that the differences between organic and conventional farming go deeper than the agronomic discussion. It is also about the perception one has of nature, agriculture, and the role men can play. Agronomists and crop scientists supporting conventional agriculture implicitly use scientific concepts and views that are common in natural sciences and are putatively value-free. Scientists supporting organic farming use concepts that go beyond those value-free scientific notions and are, therefore, challenged to make these concepts and notions explicit. This is especially true for ethical concepts and notions.

The ethical discussion in agriculture hinges on two important questions: 1. How natural is agriculture (Van Kasteren, 2002; Verhoog et al., 2003)? 2. Is the value of nature or of its living beings only instrumental or also intrinsic (cf. Krebs, 1999; Wissenburg, 2005)? Organic farming is characterized by naturalness and not only acknowledges an instrumental value of nature but also an intrinsic value. Organic farming, therefore, accepts some ethical rules that limit the control over the environment, the soil, the crops, and the animals. This is entirely in line with the true meaning of ethics in farming: ethics of farming is about recognition of and respect for limits to our freedom to use the land, nature, animals, and plants (cf. Pretty, 2002).

This paper describes the way organic farming respects these limits by analyzing its ethical notions of naturalness, intrinsic value, natural aim, and integrity of crop plants. The paper uses these notions to evaluate current techniques in plant breeding and propagation. It finally formulates the human responsibility of respect towards crop plants and their rights.

\section{NATURALNESS, INTRINSIC VALUE, AND NATURAL AIM}

Naturalness in the context of organic farming refers to

- obviating the use of synthetic agrochemicals and using organically derived substances; 
- applying organic, agro-ecological guidelines such as self-regulation; and

- respecting the specific nature or the intrinsic value of living (farm) organisms.

All these three elements refer to self-imposed, deliberately chosen limits to the freedom of manipulating, overruling, or violating nature and its resources. Therefore, through all these elements, but especially through the third element (respecting the intrinsic value), not only ecological but also ethical aspects play a significant role.

The concept of naturalness in organic farming is based on a partnership with nature. This partnership determines the basic attitude of the organic farmer towards the natural resources he is using for production, but also towards the abiotic, biotic, and social environments in which this production takes place. Moreover, the organic farmer produces for markets with specific norms and values associated with the naturalness of the production environment and, therefore, with specific demands relating to (the naturalness of) the technology used. The concept of naturalness is an essential part of the holistic nature of organic farming (Verhoog et al., 2003).

It is important to realize that the above description of naturalness completely deviates from the one commonly used by biologists working in disciplines like ecology. In the view of organic agriculture, humans are also part of the nature in agro-ecosystems. In this statement, nature is defined as "an organic environment as a whole, consisting of biotic, physical, and chemical elements, not made by man and self-regulatory"; agro-ecosystem is defined as "the ecosystem consisting of cultivated land, the inherent resources, the domesticated or wild plants contained or grown thereon, their associated domesticated or wild animals, the farmer and his household and the immediately surrounding or interlocked environment." In fact, organic agriculture does not make a strong distinction between man-independent and man-made elements in the agro-ecosystem. In this view "agri-culture" can be more or less "natural" (see also Pretty, 2002) and even the role humans play in that agri-culture can be natural as long as the above-listed guidelines are taken into account.

Also, to organic farming, it is inherent that crops and domesticated animals are managed. In this process of husbandry and handling, respect for their intrinsic value is essential, as the organic movement values plants and animals not only for their instrumental but also for their intrinsic value. In organic farming, the intrinsic value of domesticated plants and animals should by all means be respected and their "integrity" (see below) should by no means be violated. Yet, these plants and animals can be used: they have a "natural aim" (with a specific moral meaning) that fits in an organic-agricultural world order 
and this use does not violate their integrity. We derive this from the "principle for functional determinism" described for animals by Stafleu et al. (2004). This principle implies that crop plants have more value for man than just an instrumental value; crop plants exist to fulfill a certain "telos" or to accomplish a certain natural aim within agro-ecosystems, for example, to produce food for humanity in their own specific way. This aim can be human dependent and has a moral value for man. This means that when we respect both the intrinsic value of a crop plant and its functional determinism or telos, we should not interfere with its integrity, while we still can make use of it by culturing it, harvesting it, and finally eating it or using it to feed our domestic animals or as raw material for processing. Culturing can even include weeding to allow the crop plant to accomplish its aim and denying the weed to do the same, as it interferes with the natural aim of the crop plant.

The natural aim of a crop plant should not be interpreted in a narrow sense. A crop plant not only provides food, feed, or raw material, it also plays an important role in the crop rotation (e.g., by providing organic matter to the soil), in the agro-ecosystem (e.g., by harboring useful insects), and in the landscape (e.g., by influencing water flows).

To operationalize intrinsic value, we define the concept of integrity of crop plants.

\section{INTEGRITY OF CROP PLANTS}

In organic agriculture the notion is that a plant is more than the sum of its genes and biochemical pathways. It has a certain autonomy and self-regulation that leads to ascribing it an ethical, intrinsic value (or dignity). As the autonomous and self-ordering entity mainly manifests itself in a holistic view of the plant, we can also speak of the integrity of plants to indicate the ethical aspect of wholeness. For cultivated plants, integrity refers to their inherent nature, wholeness, completeness, species-specific characteristics, and their being in balance with their (organically farmed) environment, while accomplishing their natural aim. The concept of the integrity of plants makes sense only from a holistic perspective. From a reductionistic perspective, there is no focus on the whole, but on the parts. Therefore, a reductionistic approach will not be able to discover integrity and will have difficulty with sensing its relevance in the context of organic agriculture.

The integrity of crop plants manifests itself at different levels (cf. Lammerts van Bueren et al., 2003):

- Integrity of life; crop plants are self-regulating living beings that according to the organic-agricultural world order - are present in the world to accomplish a certain telos; 
- Plant-typic integrity; crop plants have a typical nature associated with the characteristics of the plant kingdom and with their natural aim within agro-ecosystems, to produce food, forage, or raw materials for humanity in their own specific way (see also our definition of nature later in this article);

- Genotypic integrity; crop plants belong to a specific species with its own nature and its own genetic variation; crop plants have a unique genotype (i.e., set of genes) that provides them the potential to have a unique expression of the combined characteristics of the species; and

- Phenotypic integrity; crop plants have a specific coherent phenotype (i.e., observable physical and chemical characteristics) that expresses their being in balance with its environment.

These elements of integrity all contribute to the unique property of plants to play a part in the cyclic nature of the system and in the system's capacity to naturally reproduce, to adjust to its environment, and to regulate itself and to be resilient. Being soil-bound means that the integrity of crop plants ("being in balance with their environment") strongly depends on the quality of the root environment and thus on the type of medium in which they are cultivated. When crop plants are grown as crops in normal soil, their integrity can remain intact. Growing plants on synthetic media already violates their integrity.

In fact, also the agro-ecosystem has its own integrity. Respecting that integrity demands a balanced attitude to all biotic and abiotic elements of the agro-ecosystem (see Pfeiffer, 1975; Baars, 1990), but this integrity is beyond the scope of this paper.

Organic agriculture will take these elements of integrity into account and will refrain from violation of integrity. Organic agriculture, therefore, accepts and cherishes the characteristic nature or way of being of living entities, including plants, their wholeness, completeness, their species-specific characteristics, and their being in balance with the species-specific environment.

\section{CRITERIA TO ASSESS INTEGRITY AND TO EVALUATE CURRENT TECHNIQUES IN PLANT BREEDING AND PROPAGATION}

Acknowledging the intrinsic value of plants and respecting their integrity in organic agriculture implies that also the breeder takes the integrity of plants into account in his choices of breeding and propagation techniques, in his design of a breeding program, in his decisions on breeding strategies, and in 
his ideas of an ideal crop plant for organic agriculture. This requires that one not merely evaluates the result and consequences of an intervention by a breeder, but in the first place questions whether the intervention itself affects the integrity of plants. From the above-described levels of the integrity of plants, a number of guidelines, characteristics, and criteria for organic plant breeding and propagation techniques can be derived. These are presented in Table 1. Applying these criteria will have far-reaching effects on the development of organic plant breeding and propagation, both as a science and as a commercial activity. Some of the consequences, as well as the reasoning behind it, are discussed below.

As a consequence of respecting integrity of life, tissue culture techniques are not desirable in organic farming, as they make use of plant parts or individual cells, which are omnipotent, but which lack the natural selfregulatory and ordering ability and require artificial (i.e., synthetic and inorganic) medium and growth regulators to regenerate into normal plants.

Respecting the plant-typic integrity demands that breeding should improve and not reduce the ability to adapt and interact with the environment, and should allow the plant to reproduce in a natural way. This means, for example, that only hybridization that results in fertile hybrids is acceptable. It also means that organic cultivars should be bred, maintained, and propagated under organic conditions, in soil. This again means that in-vitro techniques but also production systems on artificial, synthetic media are not desirable. This contrast between approaches in organic agriculture and conventional agriculture can perhaps best be illustrated by the methodology in breeding for resistance. While conventional approaches might opt for vertical (qualitative) resistance, obtained by genetic modification or protoplast fusion and selected for by employing tissue culture techniques, organic approaches will be characterized by breeding for horizontal resistance, obtained by horizontal selection on field-grown plants. This contrast is, for example, visible in breeding for late blight resistance in potato.

The genotypic integrity should be maintained, allowing the species to use its full potential of genetic variation but also respecting reproductive barriers. Genetic modification is, therefore, not accepted, but also the introduction of cytoplasmic male sterility based on alien genes should not be permitted. In respecting integrity of plants, there is no ethical or moral difference between cisgenic or intragenic modification of crops (in which genes of the same species have been inserted by genetic manipulation techniques) or transgenic modification of crops (in which genetic modification has been used to insert genes from other species) as some scientists seem to promote (see e.g., Myskja, 2004). Not only is the alien origin of the gene(s) problematic (based on the genotypic integrity), but the mere use of the technology of genetic modification at DNA level is also problematic, as 


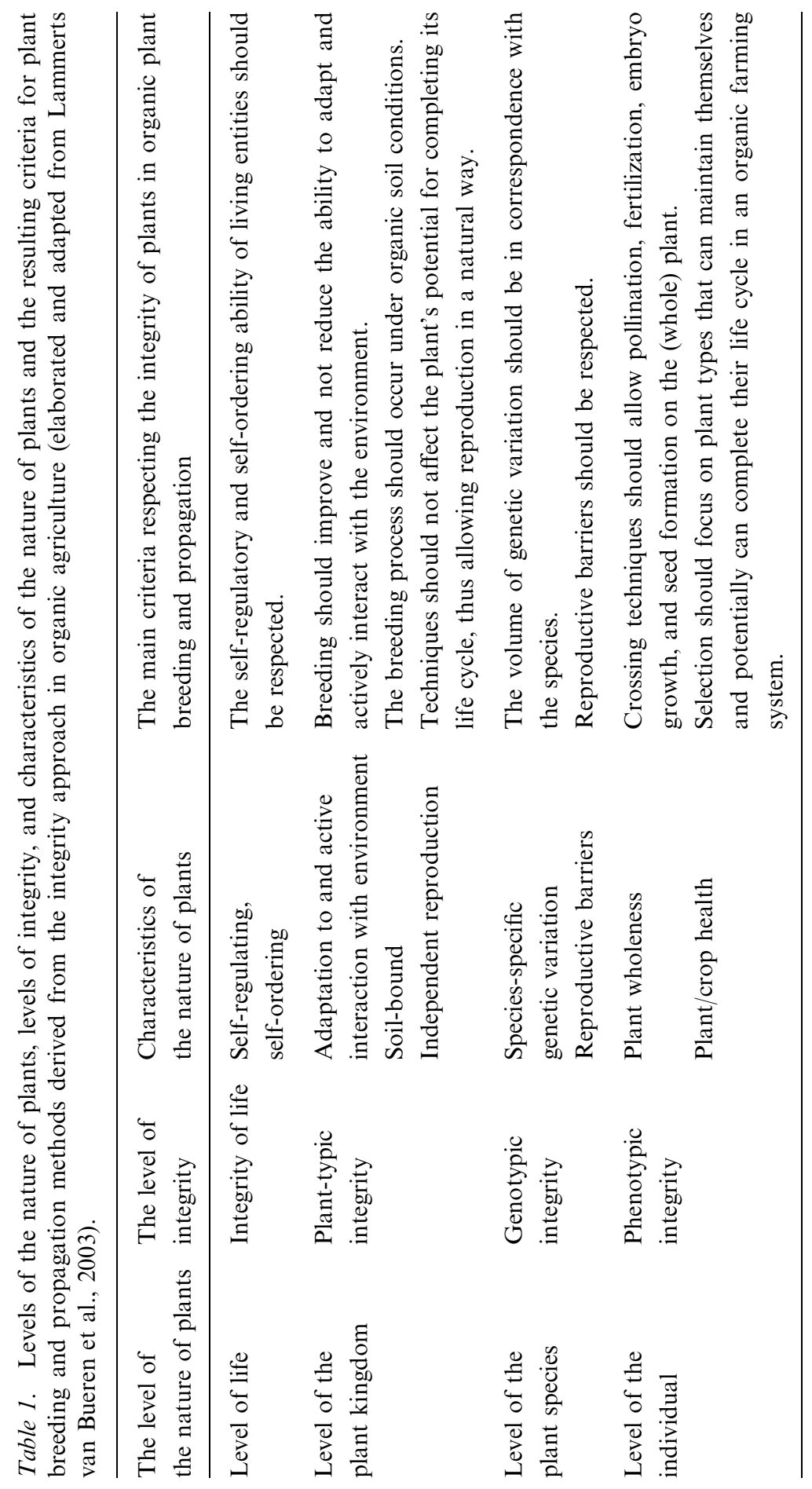


this violates the plant-typic integrity. In the latter aspect, cisgenic and transgenic modification are identical.

The phenotypic integrity means that selection should focus on plant types that can maintain themselves, can produce seeds, and can complete their life cycle in an organic farming system. The coherence of plant appearance, normal growth dynamics, and species-specific balances between quantitative and qualitative plant descriptors are also not violated. Highly productive cultivars, which are susceptible to diseases and thus dependent on the use of crop protectants, are, therefore, not desirable.

The stepwise discovery of the relevance of ethical elements in plant breeding and propagation led us to design a holistic scientific approach to organic breeding and seed production. Distinguishing different dimensions of naturalness in organic agriculture, and analyzing the consequences for breeding and propagation strategies and techniques can also help us to identify and prioritize short-term and long-term steps for the practical development of organic plant breeding and seed production. In doing so, we challenge the life sciences to participate in the discussion and to develop new and additional breeding and propagation strategies within the framework of the guidelines of naturalness to gain the desired progress for organic production. The innovative potencies of organic agriculture, also for conventional agriculture, are getting more and more recognition nowadays. As an example, we mention its impact on a more sustainable agriculture.

Our views are not final and the discussion needs to be continued and widened. There are many cases that are still to be discussed in detail to be able to decide whether they are violating the integrity or not. Obvious examples are hybridization and the use of molecular markers in organic plant breeding.

\section{COMMENTS FROM MAINSTREAM CROP SCIENTISTS AND OUR REBUTTAL}

We designed our evaluation process for two reasons. First of all, it was meant to make the implicit concepts and notions in organic farming explicit so that they could be communicated and discussed, not only within the organic movement but also with conventional farmers and mainstream scientists. Secondly, it was meant to challenge conventional crop scientists or agronomists to re-think their own, often implicit, concepts and assumptions.

Our evaluation has met considerable criticism from mainstream natural scientists (especially crop scientists; see also Lammerts van Bueren and Struik, 2005) and scientists in the field of applied philosophy. This criticism is relevant and acceptable as long as it is based on equity, i.e., as long as it questions and tests both the other's and own views with the same standards. 
In our rebuttal, we respond to the following comments or statements:

(1) Ethics cannot or should not be incorporated into objective crop sciences or agriculture (cf. Van Kasteren, 2002; Gremmen, 2004; Plasterk, 2005);

(2) There is not a basic intrinsic value in what nature has created (e.g., Morito, 2003; Wissenburg, 2005).

\subsection{Can Ethics be Incorporated into Objective Crop Sciences?}

Mainstream biologists (including ecologists, agronomists, and crop scientists) claim that the concept of naturalness is an interpretation of nature, which is restricted to a specific time and culture, and, therefore, cannot be an element in the scientific approach of the natural sciences. There are other views on nature possible and it is not up to scientists to make that choice. It is impossible to find a universal consensus about what is morally relevant with respect to plants.

We rebut with the following counter-arguments. First of all, the objectivity of science is often questionable. Incorporating ethics presents a deliberate choice for an operational framework in crop science and organic agriculture, which is better than denying such a choice, even (or especially) when it is implicitly made. Because organic agriculture operates from other values (based on non-chemical and agro-ecological guidelines and ethical approaches) than conventional agriculture, making those values explicit is necessary to understand why organic farmers restrict their management options voluntarily and why they search for other strategies. This is especially true for the ethical guidelines. Mainstream natural science is not value-free either; it has other, often less explicit values. Guidelines and choices made by researchers are usually not made explicit in research protocols, as scientists tend to neglect the impact of underlying principles in their strive for "valuefree" science (Wirz and Lammerts van Bueren, 1997; Baars, 2002). The main progress made in the thinking about ethical guidelines in organic plant breeding is that these ethical guidelines have been made explicit, have resulted in criteria, and that these criteria have been applied in an intersubjective and transparent way. In both ideologies, the one of mainstream natural science and the one of organic agriculture, man, a subjective being, is impacting nature to varying degrees, corresponding to natural, biological processes. This is a common point, only methodology and philosophy create divergence.

In response to this argumentation, mainstream crop scientists state that the organic sector is arrogant by including ethical values in its standards of action, thus giving the impression of having a higher moral standard than conventional agriculture. 
Our reply to this is as follows. The concept of naturalness is (logically) derived from the organic guidelines departing from a partner or participant attitude towards nature leading to a specific ethical framework of action. This framework is different from the framework in conventional agriculture and science, as they depart from a ruler attitude towards plant production. The conventional approach does not result in any restrictions in handling plants. It is not a matter of the organic sector having higher standards, but of having other (logically argued) standards and being clear and explicit about them. And because of this, scientists in organic farming search for alternative strategies and tools to realize their breeding objectives and the production of healthy seed in a different manner.

\subsection{What is the nature of the intrinsic value of plants in organic farming?}

Mainstream agronomists and crop scientists oppose the views of organic farming on naturalness and on the associated intrinsic value of plants. They argue that:

a. There are different interpretations of integrating nature and culture, because nature can be defined in many different ways.

b. The approach in organic farming is simply one of many views and there is no reason to assume that it will direct the actions of mankind for many generations to come.

c. The approach in organic farming surmises an intrinsic harmony, which is questionable.

d. The organic approach suggests that breeders and farmers will be stuck with a fixed image of an ideal plant based on the wild type. This consequence will be extremely counterproductive.

Our rebuttal to these arguments is that many interpretations of nature are defined at a cognitive level only, and do not fit into the definition of nature in organic agriculture. Every definition of nature is an expression of a relation between man and nature, and this relation also has an emotive dimension (attitude towards nature) and a normative dimension (idea of what we ought or not ought to do with nature). One cannot scientifically "prove" that nature has an intrinsic value; it is a moral choice, for which more or less convincing reasons can be given. The organic agricultural scientific community has made an explicit choice to adopt as definition of "natural": "that which regulates itself," as a presupposition. The word "organic" reflects the view that living nature is in the center and that nature is an organic whole. Man can interfere with nature, but within certain limits defined by the "nature" of the organisms, set by the four levels of integrity. Within these limits, ideotypes (descriptions of ideal plants of a 
specific crop for a specific agro-ecological environment) can be designed. They are dynamic and do not exclude evolution and improvement of crop performance.

\section{HUMAN RESPONSIBILITY OR PLANT RIGHTS?}

Our thinking on integrity and functional determinism of plants has been strongly influenced by the developments in the thinking on the integrity and functional determinism of animals. In the thinking about attitude towards animals in Western society, the developments have been so drastic that nowadays animal welfare and animal rights are well-known concepts, although not yet shared by everyone. Can we extrapolate these trends in the attitude towards animals to a future attitude towards plants?

Animal welfare is defined as the quality of the animal's life as perceived by the animal itself. The assessment of the perception by the animal is, however, at least partly in the eye of the beholder. Taking the concept of animal welfare as a starting point, animal rights have been drafted. Animal rights are usually formulated in the form of the five freedoms (see, e.g., Farm Animal Welfare Council, 2004):

- Freedom from thirst, hunger, and malnutrition;

- Freedom from discomfort;

- Freedom from pain, injury, and disease;

- Freedom from fear and distress;

- Freedom to express natural behavior.

Taking our notions of naturalness and integrity (or dignity) of plants as starting points, also plant rights may be drafted, in a process, comparable to the one in which animal welfare, animal rights, and the five freedoms have been formulated. However, it is obvious that most of these animal freedoms cannot be applied to plants, as plants are not sentient in the way animals are and as they are - unlike animals - soil-bound and thus stuck to the given environmental conditions.

Although plants are not sentient, Kallhoff (2002) argued that plants can have a "good life" and indicated that this good life can be promoted or harmed by man. So - although plants are different from animals - a normative attitude towards plants may still be important. Therefore, in organic agriculture, we start from the specific plant characteristics, the "nature" of plants given the moral value of the natural aim of the plants, and their naturalness, and convert those elements into human responsibility towards crop plants, which includes stewardship and caring and respect for plants. 
Given the dignity of crop plants, their natural aim, and the impact of humans on the quality of their life, humans have a moral obligation to treat crop plants according to certain plant-related standards (see also RehmannSutter, 2001). Especially in plant breeding, selection, propagation, and crop management, this will result in specific responsibilities. The more so while crop plants are purposively bred and grown, and in many cases can only survive and reproduce in the environment where they have been sown or planted if assisted to do so by their cultivators. The interdependence of mankind and crop plants requires human responsibilities and can be expressed by defining individual rights of crop plants. These should at least include:

- The right to be nurtured; and

- The right to express natural behavior at all four levels of integrity.

In the agro-ecosystem, these rights may not be restricted entirely to crop plants. To some extent, they may also apply to wild plants and even weeds, especially when these non-crop plants play a role in the stability of the agroecosystem (e.g., by hosting beneficial organisms). However, non-crop plants are only allowed when and where they do not interfere with the realization of the natural aim of the crop plants. In practice, organic farmers will remove weeds from fields. Farmers may even thin out a crop stand, if this is required to optimize the realization of the natural aim of the remaining crop plants. In field margins and other non-arable pieces of land, organic farmers allow noncrop plants to grow and often may even manage and nurture them as well.

These rights of the crop plants may be refined into the following aspects:

- The right to accomplish its natural aim in the broadest possible sense and the right to be treated as an autonomous being expressing selfregulation (integrity of life), for example, by being independent of the use of agro-chemicals for crop protection by being enabled to use its own regulatory disease control strategies;

- The right to potentially complete its life cycle (or to live out its life to its natural end) and reproduce in a plant-worthy way (plant-typic integrity), with balanced durations of the different phases and stages, adapted to the soil-borne, organically cropped environments and the intrinsic biorhythms;

- The right to co-evolve with the development of mankind but with respect for its natural reproductive barriers and its species-specific genetic variation (genotypic integrity);

- The right to be treated/nurtured in such a way that crops are able to express a sound balance between growth, development, and production (phenotypic integrity), resulting in a form and function that is consistent with the plant's nature and human intentions. 
However, there are (as in animal rights) some trade-offs between the plant rights and the objectives of the farmer in the exploitation of plants. There should also be some balance between the right to be nurtured and the right to express natural behavior. Plants are soil-bound and cannot move to avoid stress. It is, therefore, part of their naturalness to cope with relatively mild stresses, e.g., by advancing reproductive growth and development. Crop management can even include purposely imposing some stress, e.g., forcing plants to flower and set seed when growing crops for seed production. Similarly, freedom from other forms of discomfort associated with the crop situation is also not included in the plant rights. In agriculture, plants are often grown in a sub-optimal way that is discomforting for plants, in the sense that husbandry induces abnormal behavior: soil compaction will cause abnormal root thickening, high densities will induce strong elongation growth; but organic plant breeding strives for plants that show resilience and robustness by adjusting to an environmental factor and by finding a new balance between growth, development, and finalizing its life cycle, still being able to execute its other rights.

\section{CONCLUSIONS}

An essential part of the naturalness of organic farming is its respect for the natural aim and the intrinsic value of plants. This respect can be operationalized in ascribing ethical value to the aim and to the four levels of integrity: integrity of life, plant-typic integrity, genotypic integrity, and phenotypic integrity. The resulting ethical criteria can be consistently applied in the sciences of organic plant breeding and propagation. This will provide new challenges to the organic plant breeding strategies and will result in crop cultivars being produced and multiplied more in line with the approaches of organic agriculture. The dos and don'ts can also be translated into respect towards crop plants or even into crop plant rights defining the responsibility of their cultivaters towards managing crop plants.

\section{ACKNOWLEDGEMENT}

The authors thank Dr. Henk Verhoog for his valuable comments on an earlier version of the manuscript. 


\section{REFERENCES}

Baars, T., Het bosecosysteem als beeld van het bedrijfsorganisme in de biologischdynamische landbouw (Louis Bolk Institute, Driebergen, The Netherlands, 1990) ["The forest ecosystem as image of the farm organism in the biological-dynamic agriculture'].

Baars, T., Reconciling scientific approaches for organic agricultural research. $\mathrm{PhD}$ dissertation (Wageningen University, Wageningen, 2002).

Bindraban, P., "Hoe lang nog duurt de biologische hype? Met een blinde vlek voor sociale rechtvaardigheid." ["How long will the organic hype last? With a blind spot for social justice"], Spil 199-200 (2004) pp. 18-20.

Farm Animal Welfare Council (2004), Farm Animal Welfare. http://www.fawc. org.uk [date accessed: 02/05/2004].

Gremmen, B., "Intrinsic Value and Plant Genomics," in J. H. Tavernierde and S. Aerts (eds.), Science, Ethics \& Society (Katholieke Universiteit Leuven, Leuven, 2004), 145-147. 5th Congress of the European Society for Agricultural and Food Ethics.

Kallhoff, A., Prinzipien der Pflanzenethik. Die Bewertung pflanzlichen Lebens in Biologie und Philosophie (Campus Forschung, Frankfurt (Main), 2002) [Principles of plant ethics. The valuation of plant life in biology and philosophy].

Krebs, A., Ethics of Nature - A Map (De Gruyter, Berlin, New York, 1999).

Lammerts van Bueren, E. T. and P. C. Struik, "Integrity of Plants: The Missing Element in a Holistic View on Organic Plant Breeding and Propagation," in Proceedings Such is Life, Reconciling reductionism and holism. (Louis Bolk Institute, Driebergen, 2005) (in press).

Lammerts van Bueren, E. T., P. C. Struik, M. Tiemens-Hulscher, and E. Jacobsen, "The Concepts of Intrinsic Value and Integrity of Plants in Organic Plant Breeding and Propagation," Crop Science 43 (2003), 1922-1929.

Morito, B., "Intrinsic Value: A Modern Albatross for the Ecological Approach," Environmental Values 12 (2003), 317-336.

Myskja, B. K., "Is There a Moral Difference Between Intragenic and Transgenic Modification of Plants?" in J. H. Tavernierde and S. Aerts (eds.), Science, Ethics \& Society (Katholieke Universiteit Leuven, Leuven, 2004), 141-144. 5th Congress of the European Society for Agricultural and Food Ethics.

Pfeiffer, M. W., Die landwirtschafliche Individualität - ein Bild eines Menschen. [The agricultural individuality - an image of man]. (Selbstverlag, Borchen, Deutschland, 1975).

Plasterk, R., "The Emancipation of Ethics," in Ethics in Science, 87th Dies Natalis (Wageningen: Wageningen University and Research Centre, 2005) pp. 7-13.

Pretty, J., Agri-culture. Reconnecting People, Land and Nature (Earthscan Publications, London, 2002).

Rehmann-Sutter, C., "Dignity of Plants and Perception," in D. Heaf and J. Wirz (eds.), Intrinsic Value and Integrity of Plants in the Context of Genetic Engineering. Proceedings of Workshop (Ifgene, Dornach, 2001), pp 4-8.

Stafleu, F. R., C. C. Lauwere, and K. H. Greef, "Respect for Functional Determinism. A Farmer's Interpretation of 'Respect for Animals'," in J.H. Tavernierde and S. Aerts (eds.), Science, Ethics \& Society (Katholieke Universiteit Leuven, Leuven, 2004), 73-75. 5th Congress of the European Society for Agricultural and Food Ethics. 
Van Kasteren, J., "Dure reclamecampagne van LNV voor biologische producten. Versterking van taboes belemmert duurzame ontwikkeling," ["Expensive advertizing campaign of the Ministry of Agriculture, Nature and Food Quality for organic products. Strengthening taboos impedes sustainable development'], Spil 185-186 (2002) pp. 5-8.

Verhoog, H., M. Matze, E. Lammerts van Bueren, and T. Baars, "The Role of the Concept of the Natural (Naturalness) in Organic Farming," Journal of Agricultural and Environmental Ethics 16 (2003), 29-49.

Wirz, J. and E. Lammerts van Bueren(eds.), The Future of DNA. Proceedings of an International Ifgene Conference on Presuppositions in Science and Expectations in Society (Kluwer Academic Publishers, Dordrecht, 1997).

Wissenburg, M. L. J., "Mens, natuur en onderwerping. Een humanistisch perspectief op de intrinsieke waarde van de natuur," ["Man, nature and submission. A humanistic perspective on the intrinsic value of nature"], Inaugurele rede (Leerstoelgroep Toegepaste Filosofie, Wageningen Universiteit, Wageningen, 2005).

\section{Louis Bolk Institute}

Hoofdstraat 24,

3972 LA Driebergen,

The Netherlands

E-mail:E.Lammerts@louisbolk.nl

Wageningen University

Plant Sciences Group

Crop and Weed Ecology

Haarweg 333, 6709 RZ Wageningen

The Netherlands

Tel.: + 31-317-484246

Fax: +31-317-485572

E-mail:Paul.Struik@wur.nl 